\title{
Divulgación Cientifica
}

\section{Nomenclatura de esteroides}

El siguiente documento es una versión de las recomendaciones (1989) dadas por la IUPAC, para la nomenclatura de esteroides.

http://www.chem.qmul.ac.uk/iupac/steroid/3S01.html\#3S15

Para una representación en perspectiva de la estereoquímica de la siguiente estructura:

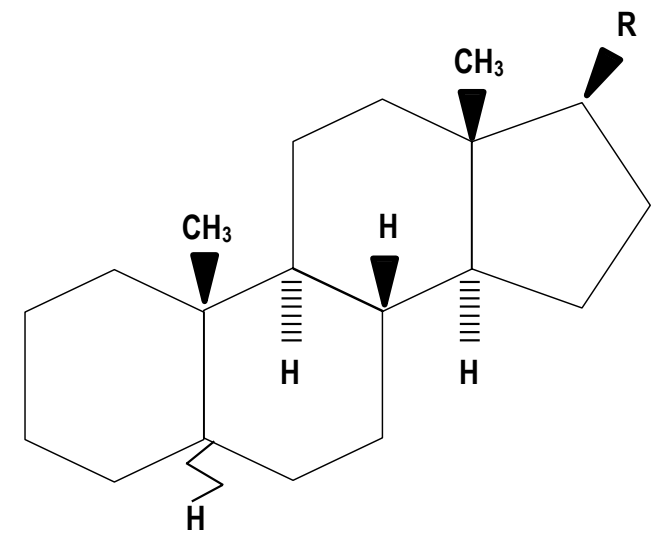

Se pueden utilizar las fórmulas que se presentan a continuación:

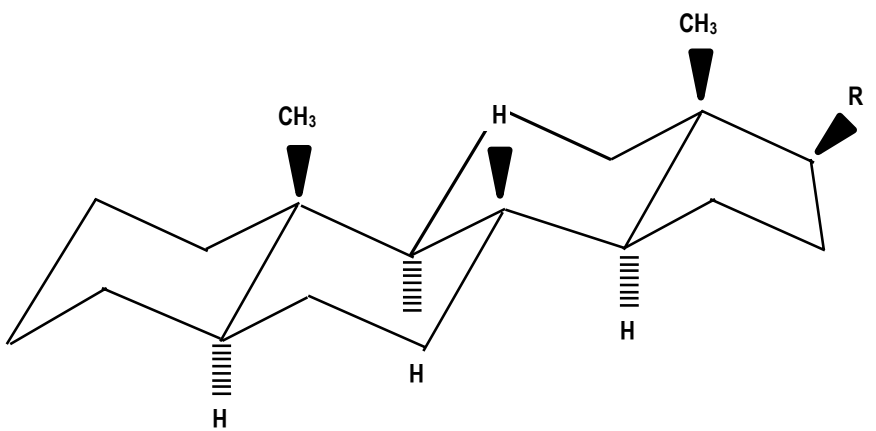

(2f)

Un esteroide 5 alfa

Cuando se utilizan estas fórmulas para representar esteroides, por convención, los grupos que se dirigen hacia arriba se unen utilizando enlaces en forma de "cuña" y los que se dirigen hacia abajo, se unen utilizando enlaces en forma de trazos.

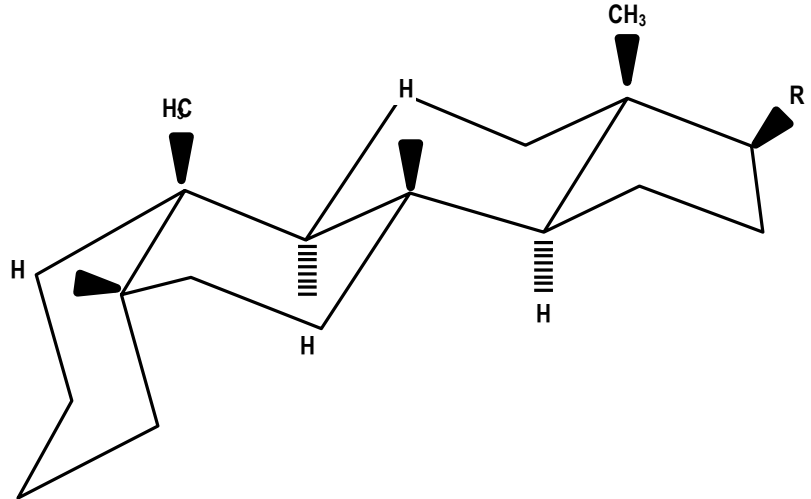

(2g)

Un esteroide 5 beta

Es necesario anotar que estas representaciones no se ajustan a la práctica general que los enlaces en forma de "cuña” y los de líneas de trazos no están por encima ni por debajo, respectivamente, del plano del papel.

Para ahorrar espacio y enfatizar la parte pertinente de la fórmula de esteroides, se puede utilizar la siguiente forma:

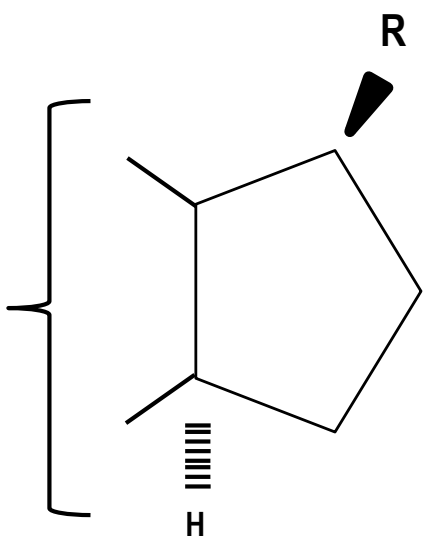

(2h)

Aquí se muestra solamente el anillo $D$ y la cadena lateral de C17, se debe asumir que el resto de la molécula es el anillo del androstano (2g). 
Carbociclos fundamentales, insaturaciones y grupos alquilo en la sustitución en C17

El hidrocarburo tetracíclico "padre", sin grupos metilo en C10 y C13 y sin cadena lateral en C17, se le da el nombre de gonano (ver estructuras 9 y 10 ).
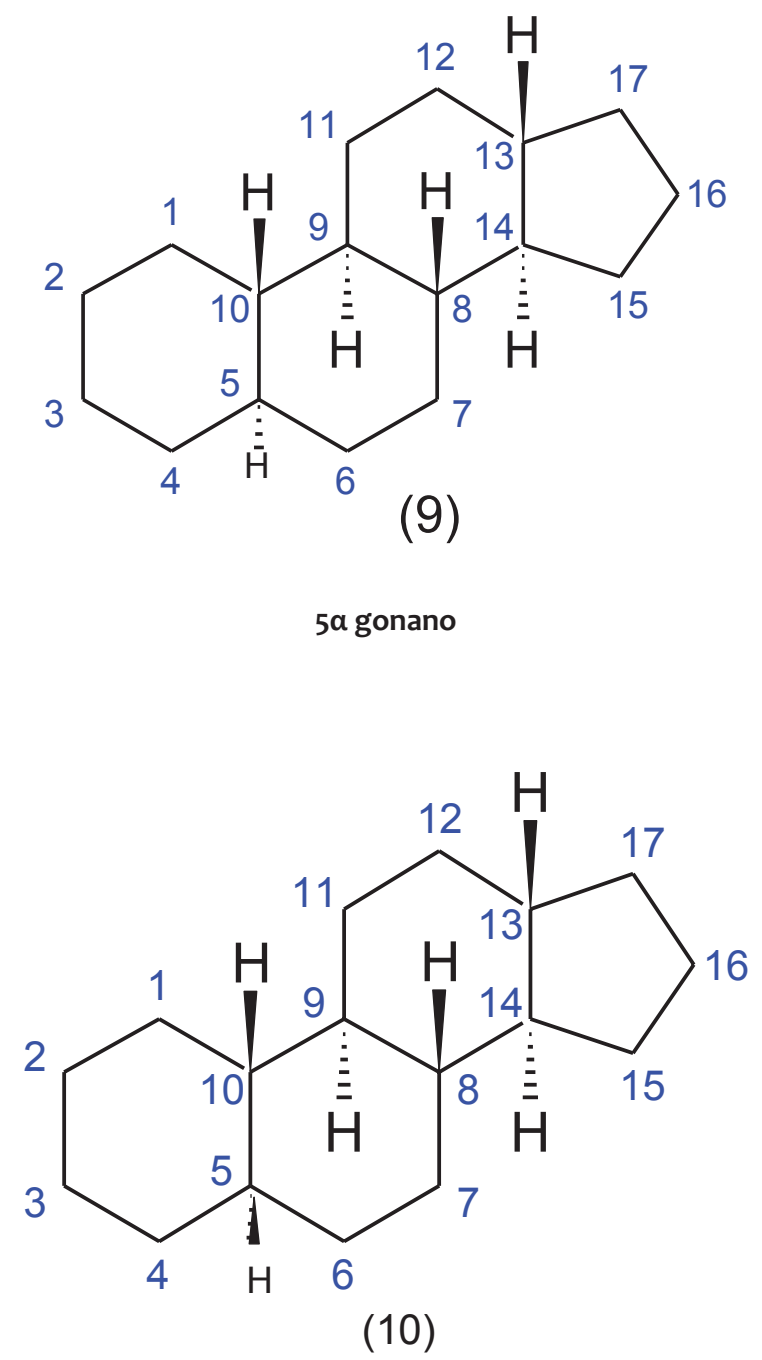

$5 \beta$ gonano

El hidrocarburo con un grupo metil en $\mathrm{C} 13$ pero no en $\mathrm{C} 10$ y sin cadena lateral en C17, se nombra como estrano, o también oestrano (ver estructuras 11 y 12).

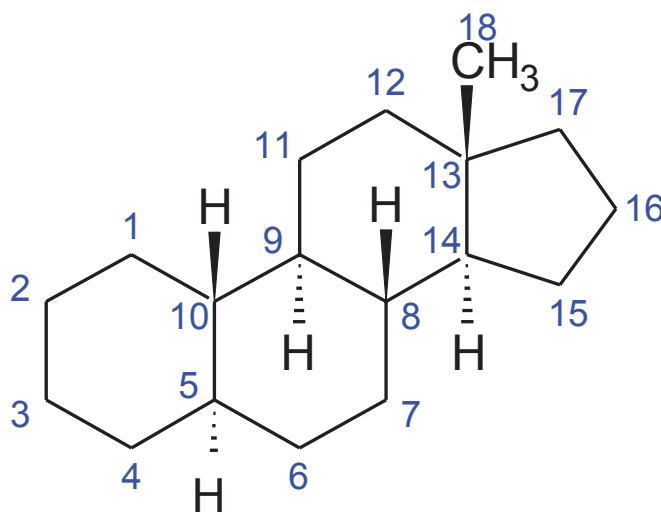

11

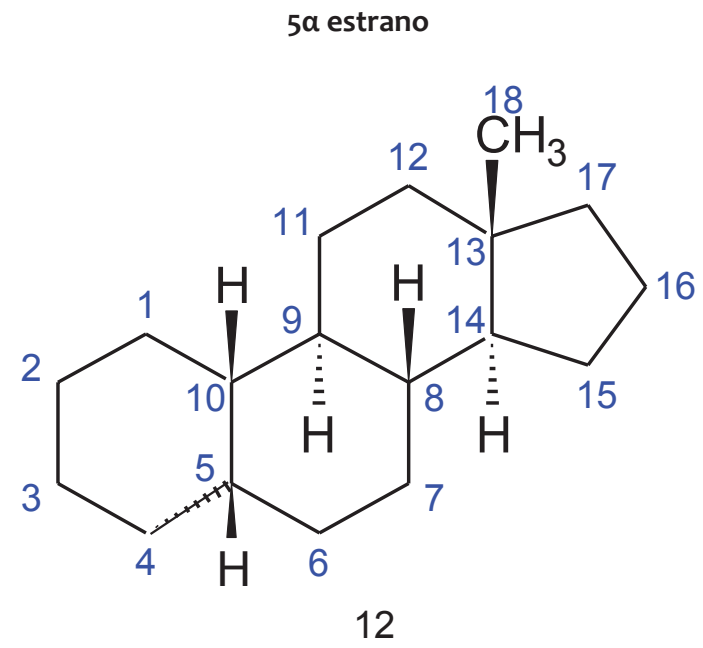

$5 \beta$ estrano

El hidrocarburo con grupos metil en $\mathrm{C}_{10}$ y C13, pero sin cadena lateral en $\mathrm{C} 17$ es llamado androstano (ver figuras 13 y 14 ).

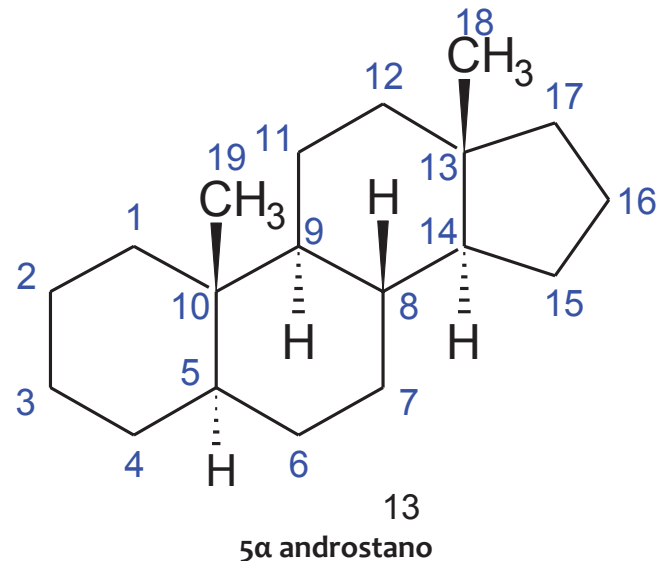




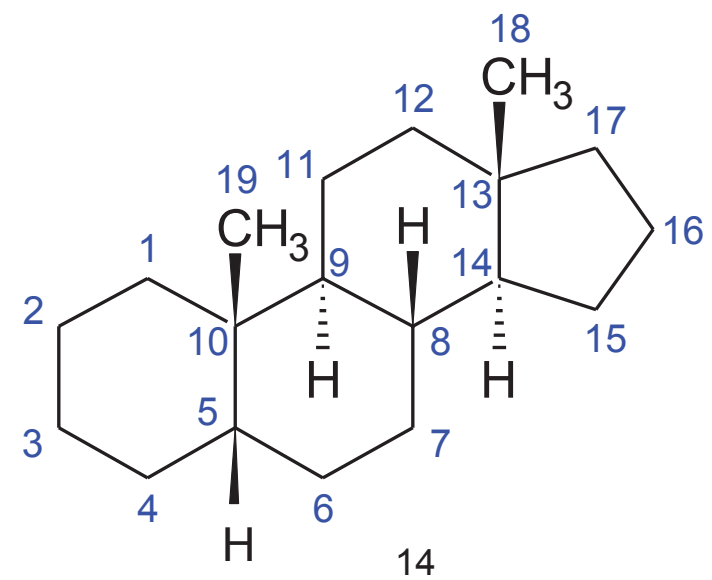

$5 \beta$ androstano

Es necesario recordar que la diferencia en la estereoquímica del átomo de carbono, $\mathrm{C}_{5}$, determina la estereoquímica alfa o beta de las estructura mostradas anteriormente.

Para los nombres de los hidrocarburos que tienen un grupo metil en $\mathrm{C} 10 \mathrm{y}$ un átomo de hidrógeno en C13, o compuestos en los que el grupo metil se reemplaza por el grupo etil, se puede consultar la sección 3S - 6 en: http://www.chem.qmul.ac.uk/ iupac/steroid/3So6.html

Los nombres de hidrocarburos con grupos metil en $\mathrm{C} 10$ y $\mathrm{C} 13$ y con cadena lateral en C17, se listan en la tabla 1 en: http://www.chem.qmul.ac.uk/iupac/steroid/tab1.html

En próximas ediciones del Boletín PPDQ se continuará con este tema. 